\section{The conqueror worm?}

\section{Len Goodwin}

A History of Human Helminthology. By David Grove. C.A.B. International: 1990. Pp. 848. £55, \$104.50.

WORMs, from mythical dragons to microscopic parasites, have always been a source of fascination. The name itself is an indefinite, emotive and evocative term for "any elongated creeping thing that is not obviously somcthing clse". Linnaeus used the title Vermes as an all-embracing description for all worm-like creatures: earthworms; insect larvae in fruit, vegetables and trees; parasites in animals and a wide range of other invertebrates. Originally thought to be generated spontaneously in decaying matter and ordure, it took a long time to sort them all out.

When Harold Scott wrote his History of Tropical Medicine (Edward Arnold) in 1939 he thought that ankylostomiasis was "almost the only helminthic infestation of man in the tropics which can be said to have a history, at all events a history of sufficient interest to call for any detail" and he made no mention of any other. He was quite wrong; the stories have all the fascination of good detective yarns. David Grove, of the Department of Clinical Microbiology and Infectious Diseases, Queen Elizabeth Hospital, Woodville, South Australia, who has worked on worm infections in tropical countries, has now written a definitive history of human helminthology. He regards it as a labour of love over the past 12 years, one of them spent as a sabbatical in Britain with access to the data of the Tropical Diseases Bulletin, in which the world's helminthological literature has been abstracted since the turn of the century. Detailed and comprehensive, it puts into historical context the discoveries of all those who worked in the field, from the disproof of early theories of spontaneous generation to the systems of classification developed in the eighteenth and nineteenth centuries and the more recent elucidation of life cycles and epidemiology.

There are three chapters of introduction (on classification, general history and the development of anthelmintics), eight on flukes (trematodes), five on tapeworms (cestodes), 11 on roundworms (nematodes) and one on miscellaneous matters such as imaginary worms and pseudoparasites. For each species the discovery of the parasite, its life cycle, clinical manifestations, diagnosis, treatment, epidemiology, preventive and control measures are all covered. Every chapter has a long, valuable list of references to original publications. Writing in a clear, direct narrative style, Grove retains the reader's attention and interest, even in the more involved arguments and disputes some of them acrimonious and refreshingly robust - that took place between the holders of rival theories until someone did the right experiment to settle the matter.

A History of Human Helminthology is full of good stories. Detailed descriptions are given of the ways in which a guinea worm may be removed, by winding it out on a stick or by snicking the skin at a point half way along and lifting it out with a hook. And there is the intriguing series of disputes on the mode of transmission of Japanese schistosomiasis, settled conclusively by Fujinami in 1909 by showing that cattle, if allowed to walk in the rice paddies acquired heavy infections but did not do so if protected with Wellington boots. The fortitude and devotion to scientific discovery of the early field workers is also impressive. When Arthur Looss (a German with a dogmatic, acrid, controversial style) was working in Cairo at the turn of

\section{The joy of systematics}

Thomas D. Kocher

Molecular Systematics. Edited by David M. Hillis and Craig Moritz. Sinauer: 1990 Pp. 588. Hbk £52, \$65; pbk £29.95, $\$ 37.95$.

NEW techniques arise with alarming frequency in molecular systematics. With so many options, it is difficult for novices to determine which method to use for a particular problem. Too often the choice is made not on the merits of a particular approach but by more practical considerations: Dr know-it-all is already using the procedure down the hall. Thus a book that accomplishes a rational evaluation of currently used techniques, as this one does, is most welcome.

As a compendium of classical techniques in molecular systematics, this book will have enduring value. Introductory chapters describe sampling design and give practical details of specimen collection in the field. At the core of the book are six chapters covering the basic methodologies of molecular systematics: isozyme electrophoresis, immunology, cytogenetics, DNA hybridization, restriction fragment analysis and nucleic-acid sequencing. Careful guidance by the editors has resulted in chapters with a uniform appearance and content. Extensive use of figures helps to make the book very readable, despite its encyclopaedic nature. The clear presentation of practical details in experimental protocols makes the book immediately useful in the laboratory. Two final chapters describe the analysis of the century, the treatment for hookworm disease was unpleasant and uncertain. But having noticed that burning and redness occurred when he accidentally spilt a suspension of hookworm larvae on his skin, he repeated the process, showed that the larvae disappeared and that later, the numbers of hookworm eggs in his stools increased. This was momentous because it was the first time that the percutaneous penetration of any worm was shown.

The book ends with the potted biographies of some 130 prominent personalities in the field, together with their portraits. This helps to bring the text alive - it makes all the difference to know what the actors in the drama looked like. No detailed knowledge of helminthology is assumed and the stories can be enjoyed by all. A splendid achicvement, certain to become the standard text on the history of human helminthology for many years.

Len Goodwin is at Shepperlands Farm, Park Lane, Finchampstead, Berkshire RG11 4QF. UK.

data. The chapter by E.L. Swofford and G.J. Olsen on the various algorithms for estimating phylogenies is a real jewel. Each method, and its assumptions, are clearly laid out with a good mix of text, equations and figures. It serves well as a text for graduate-level lectures in phylogenetic reconstruction. Weir's chapter on the analysis of intraspecific differentiation is less successful. Its elegant content will remain inaccessible to most readers. A final chapter by the editors makes recommendations on the choice of techniques for a particular problem.

If the book has a flaw, it is the absence of chapters on molecular evolution. For too long, systematists have proceeded as if the field of molecular evolution had nothing to do with the problems of molecular systematics. Continued emphasis on techniques and algorithms, rather than on a mechanistic understanding of molecular function and the pattern of nucleotide replacement, has led to errors in the interpretation of phylogenies from molecular sequences. Nowhere in this book is the considerable literature on these topics reviewed. Nor is there guidance on choosing nucleotide characters for analysis. These omissions make the book more retrospective than prescient. Increasingly, molecular systematists are finding the direct determination of DNA sequences a practical alternative to more indirect methods of measuring genetic difference. To estimate phylogenies accurately from these nucleotide sequences will require a more complete understanding of evolution at the molecular level than this book can provide.

Thomas D. Kocher is in the Department of Zoology, University of New Hampshire, Durham, New Hampshire 03824, USA. 